\section{References}

${ }^{1}$ Aston SJ, Longmire WP. Pancreaticoduodenal resection. Twenty years' experience. Arch Surg 1973;106:813-7.

2 Warren KW, Choe DS, Plaza J, Relihan M. Results of radical resection for periampullary cancer. Ann Surg 1975;181:534-9.

${ }^{3}$ Braasch JW, Gray BN. Considerations that lower pancreaticoduodenectomy mortality. Am f Surg 1977;133:480-5.

${ }^{4}$ Child CG, Hinerman DL, Kauffman GL. Pancreaticoduodenectomy. Surg Gynecol Obstet 1978;147:529-33.

${ }^{5}$ Forrest JF, Longmire WP. Carcinoma of the pancreas and periampullary region. Ann Surg 1979;189:129-38.

${ }^{6}$ Blumgart LH, Kennedy A. Carcinoma of the ampulla of Vater and duodenum. Br 7 Surg 1973;60:33-40.

7 Webster DJT. Carcinoma of the pancreas and periampullary region: a clinical study in a district general hospital. Br $\mathcal{F}$ Surg 1975;62:130-4.

${ }^{8}$ Langer B, Lipson R, McHattie JD, et al. Periampullary tumours: advances in diagnosis and surgical treatment. Can $\mathcal{F}$ Surg 1979;22:34-7.
${ }^{9}$ Monge JJ, Judd ES, Gage RP. Radical pancreaticoduodenectomy: a 22 year experience with the complications, mortality rate and survival rate. Ann Surg 1964;160:711-22.

10 Sato T, Saitoh Y, Koyama K, Watanabe K. Pre-operative determination of operability in carcinomas of the pancreas and the periampullary region. Ann Surg 1968;168:876-86.

11 Ponka JL, Uthappa NS. Carcinoma of the ampulla of Vater. Am $\mathcal{F}$ Surg $1971 ; 121: 263-70$.

12 Sato T, Saitoh Y, Noto N, Matsuno S. Follow-up studies of radical resection for pancreaticoduodenal cancer. Ann Surg 1977;186:581-8.

${ }^{13}$ Liguory C, Loriga P. Endoscopic sphincterotomy. Am f Surg 1978;136: 609-13.

${ }^{14}$ Safrany L. Endoscopic treatment of biliary-tract diseases. Lancet 1978;iv: 983-5.

(Accepted 6 February 1981)

\title{
Five year follow-up of effects of treatment of mild and moderate hypertension
}

\author{
J A P TRAFFORD, C R HORN， H O’NEAL， R MCGONIGLE， L HALFORD-MAW， R EVANS
}

\begin{abstract}
A five-year follow-up study of the effects of treating patients with both mild and moderate hypertension was performed. The patients were identified during a hospital-based community survey of hypertension. A total of 961 patients were divided into four groups. The first group, the controls, were age- and sex-matched normotensive subjects selected sequentially from the same survey. The second group were patients defined as wellcontrolled hypertensives; the third group were patients whose blood pressures were less well-controlled; and the fourth group consisted of patients who, for various reasons, were not treated and as such acted as an untreated control group. Both mortality and morbidity were considerably greater in the untreated patients than in the normal subjects. The well-controlled hypertensive patients showed no difference in either morbidity or mortality from normal subjects. The less well-controlled patients had a significantly greater cardiovascular morbidity but no excess mortality over groups 1 and 2. This was true for both mild and moderate hypertension and for women as well as men.

These findings therefore confirm the conclusions of other recent studies that good control of hypertension at all levels and in both sexes is justified by the reduction in morbidity and that even less than excellent control is of considerable benefit.
\end{abstract}

\section{Introduction}

The treatment of moderate to severe hypertension reduces morbidity and mortality, ${ }^{12}$ and recent studies ${ }^{3-5}$ have suggested that the same is true for mild hypertension. A weakness of the

Royal Sussex County Hospital, Brighton BN2 5BE

J A P TRAFFORD, FRCP, consultant physician and director of the renal unit C R HORN, MB, MRCP, research fellow

H O'NEAL, MRCP, medical registrar

R MCGONIGLE, MRCP, medical registrar

L. HALFORD-MAW, research administrator

R EVANS, SRN, nursing officer, renal unit two most recent surveys of the treatment of mild hypertension has been the lack of control groups, whether of normotensive or of uncontrolled subjects, and therefore only groups of patients on differing levels of treatment have been compared.

We compared the morbidity and mortality of treated and untreated patients with mild and moderate hypertension. Three distinct groups of patients with well-controlled, moderately controlled, and uncontrolled hypertension were compared with a normotensive group of age- and sex-matched controls. We report the results of our follow-up after five years and compare our results and conclusions with those of other studies.

\section{Patients and methods}

Asymptomatic hypertension was detected in the community by a hospital-based survey using a programme of home visits, details of which have already been published. ${ }^{6}$ Hypertension was defined as a systolic blood pressure over $140 \mathrm{~mm} \mathrm{Hg}$ or a diastolic pressure (phase 5) over $95 \mathrm{~mm} \mathrm{Hg}$. All patients who were selected in this series had their blood pressure taken on two separate occasions at home and on a further two occasions in a hospital clinic before they were included as hypertensive by the above criteria. During the study a series of age- and sex-matched normotensive controls were also recruited. A total of 961 patients were recruited, of whom 382 formed the normotensive control group (group 1); 392 formed the wellcontrolled hypertensive group (group 2), defined as those whose blood pressure on more than $80 \%$ of occasions was below $140 / 95 \mathrm{~mm} \mathrm{Hg}-$ that is, resorted to our arbitrarily defined normal levels. Group 3 comprised 111 patients whose blood pressure was above $140 / 95 \mathrm{~mm}$ $\mathrm{Hg}$ on at least $20 \%$ of occasions. Group 4 comprised 76 patients who, for various reasons (including patient and doctor preference) remained untreated and formed a hypertensive control group. All patients were followed up for five years and were seen regularly.

The antihypertensive drugs used in this study were beta-blocking agents except where contraindicated; $98 \%$ of patients received these agents. At each visit blood pressure was checked and cardiovascular morbidity recorded. For those patients who had died, the cause of death was recorded either from our own knowledge or the general practitioner's records and checked with the relatives. Cardiovascular morbidity was defined as transient cerebral ischaemic attacks, completed cerebrovascular accidents, hypertensive encephalopathy, cardiac failure, cardiac infarction, or myocardial ischaemic episodes. There was one case of aortic aneurysm.

During the study a history of smoking, dietary, and exercise habits was also recorded but no advice was given on these habits. The records of the lipid values and other investigative findings formed part of a separate study and are not recorded here. 


\section{Results}

The distribution by age, sex, and initial diastolic blood pressure of all patients is shown in table I. The sex distribution was similar. Group 4, however, included more patients with mild hypertension than with severe hypertension. The subjects in group $\mathbf{4}$ were slightly older but this difference was not significant.

The cumulative mortality is shown in tables II-V and in the figure. There were no deaths from non-cardiovascular causes in the hypertensive subjects but $6(67 \%)$ deaths in the normotensive subjects were non-cardiovascular. There was considerable excess mortality in group $4(17.1 \% v 2.3 ; \mathrm{p}<0.001)$. The cumulative total mortality in the treated groups was not significantly higher than in group 1. Women had a lower mortality than men in groups 1,2 , and 3 but this was not statistically significant.

Tables IV and V show the incidence of cerebrovascular disease and ischaemic heart disease respectively. Group 2 showed no excess mortality at any initial blood pressure level or in either sex. In group 3, however, although there was no excess mortality in patients with mild hypertension, there was a small but significant increase in mortality from ischaemic heart disease in those with moderate hypertension $(3.1 \% v 0.5 \% ; p<0.05)$. Group 4 showed pronounced excess morbidity at all initial blood pressure levels, and although women did fare slightly better than men the difference was not significant. Group 2 had no excess morbidity and this was true for all initial blood pressure levels in both sexes. Group 3 showed an increase in cardiovascular morbidity for both mild and moderate hypertension and for both sexes at all ages. The patients with mild hypertension in this group, however, although suffering a significantly increased incidence of cerebrovascular accidents, showed no significant excess non-fatal ischaemic heart disease. Those with moderate hypertension in group 3 with initial diastolic pressures of $105 \mathrm{~mm} \mathrm{Hg}$ or more showed an increased cardiovascular morbidity of all types.

When our hypertensive patients in groups 2 and 3 were redistributed according to whether they had been treated in the hospital clinic or in the community the two resulting groups were almost interchangeable with the existing groups 2 and 3.

TABLE I-Distribution of patients by age, sex, and initial diastolic blood pressure

\begin{tabular}{|c|c|c|c|c|}
\hline & $\underset{(\mathrm{n}=382)}{\text { Group } 1}$ & $\underset{(\mathrm{n}=392)}{\text { Group 2 }}$ & $\begin{array}{c}\text { Group } 3 \\
(\mathrm{n}=111)\end{array}$ & $\begin{array}{l}\text { Group } 4 \\
(n=76)\end{array}$ \\
\hline \multicolumn{5}{|l|}{$\begin{array}{l}\text { Blood pressure }(\mathrm{mm} \mathrm{Hg}): \\
<95\end{array}$} \\
\hline $\begin{array}{l}95-104 \\
>104\end{array}$ & & 152 & $\begin{array}{l}46 \\
65\end{array}$ & $\begin{array}{l}46 \\
30\end{array}$ \\
\hline Mean age (years) & $58 \cdot 3$ & $56 \cdot 4$ & $61 \cdot 6$ & $62 \cdot 0$ \\
\hline Sex: & & & & \\
\hline $\begin{array}{l}\text { Men } \\
\text { Women }\end{array}$ & $\begin{array}{l}195 \\
187\end{array}$ & $\begin{array}{l}177 \\
215\end{array}$ & $\begin{array}{l}54 \\
57\end{array}$ & $\begin{array}{l}34 \\
42\end{array}$ \\
\hline
\end{tabular}

TABLE II-Five-year cumulative mortality (\%) by initial blood pressure

\begin{tabular}{lcccc}
\hline & $\begin{array}{c}\text { Group 1 } \\
(\mathrm{n}=382)\end{array}$ & $\begin{array}{c}\text { Group 2 } \\
(\mathrm{n}=392)\end{array}$ & $\begin{array}{c}\text { Group 3 } \\
(\mathrm{n}=111)\end{array}$ & $\begin{array}{c}\text { Group 4 } \\
(\mathrm{n}=76)\end{array}$ \\
\hline $\begin{array}{l}\text { All patients } \\
\text { Patients with blood }\end{array}$ & $2 \cdot 3$ & 0.5 & 3.6 & $\begin{array}{c}17 \cdot 1^{*} \\
\text { pressure of 95-104 mm Hg }\end{array}$ \\
$\begin{array}{c}\text { Patients with blood } \\
\text { pressure above 104 mm Hg }\end{array}$ & & 0.7 & $2 \cdot 2$ & $21 \cdot 7^{*}$ \\
\end{tabular}

${ }^{*} \mathrm{p}<0.001,+\mathrm{p}<0.05$ compared with mortality in group 1.

TABLE III-Five-year cumulative mortality (\%) by sex

\begin{tabular}{|c|c|c|c|c|}
\hline & $\begin{array}{c}\text { Group } 1 \\
(\mathrm{n}=382)\end{array}$ & $\begin{array}{c}\text { Group 2 } \\
(\mathrm{n}=392)\end{array}$ & $\begin{array}{c}\text { Group } 3 \\
(\mathrm{n}=111)\end{array}$ & $\begin{array}{l}\text { Group } 4 \\
(n=76)\end{array}$ \\
\hline $\begin{array}{l}\text { All patients: } \\
\text { Men } \\
\text { Women }\end{array}$ & $\begin{array}{l}4.0 \\
0.5\end{array}$ & $1 \cdot 1$ & $\begin{array}{l}5 \cdot 6 \\
1.8\end{array}$ & $\begin{array}{l}14.7^{*} \\
19.0 \dagger\end{array}$ \\
\hline $\begin{array}{l}\text { Patients with blood } \\
\text { pressure of } 95-104 \mathrm{~mm} \mathrm{Hg} \text { : } \\
\text { Men } \\
\text { Women }\end{array}$ & & $1 \cdot 1$ & $4 \cdot 8$ & $\begin{array}{l}16 \cdot 7 \dagger \\
27 \cdot 3 \dagger\end{array}$ \\
\hline
\end{tabular}

${ }^{*} \mathrm{p}<0.05,+\mathrm{p}<0.001$ compared with mortality in group 1.
TABLE IV-Five-year morbidity and mortality (\%) for cerebrovascular disease by initial diastolic blood pressure

\begin{tabular}{|c|c|c|c|c|}
\hline & $\begin{array}{l}\text { Group } 1 \\
(\mathrm{n}=382)\end{array}$ & $\begin{array}{c}\text { Group 2 } \\
(\mathrm{n}=392)\end{array}$ & $\begin{array}{c}\text { Group } 3 \\
(n=111)\end{array}$ & $\begin{array}{l}\text { Group 4 } \\
(n=76)\end{array}$ \\
\hline $\begin{array}{l}\text { All patients: } \\
\text { Morbidity } \\
\text { Mortality }\end{array}$ & 0.3 & 0.5 & $10 \cdot 8^{*}$ & $\begin{array}{l}1.3 \dagger \\
9.2^{*}\end{array}$ \\
\hline $\begin{array}{l}\text { Patients with blood } \\
\text { pressure of } 95-104 \mathrm{~mm} \mathrm{Hg} \text { : } \\
\text { Morbidity } \\
\text { Mortality }\end{array}$ & & 1.7 & $4 \cdot 3 *$ & $\begin{array}{l}2 \cdot 2 \dagger \\
8 \cdot 7^{*}\end{array}$ \\
\hline $\begin{array}{l}\text { Patients with blood } \\
\text { pressure of over } 104 \mathrm{~mm} \mathrm{Hg} \text { : } \\
\text { Morbidity } \\
\text { Mortality }\end{array}$ & & & $5 \cdot 2 *$ & $3 \cdot 3+$ \\
\hline
\end{tabular}

${ }^{*} \mathrm{p}<0.001,+\mathrm{p}<0.01, \ddagger \mathrm{p}<0.05$ compared with morbidity and mortality in group 1.

TABLE V-Five-year morbidity and mortality (\%) for ischaemic heart disease by initial blood pressure

\begin{tabular}{|c|c|c|c|c|}
\hline & $\underset{(n=382)}{\text { Group } 1}$ & $\underset{(\mathrm{n}=392)}{\text { Group } 2}$ & $\begin{array}{l}\text { Group } 3 \\
(n=111)\end{array}$ & $\begin{array}{l}\text { Group } 4 \\
(n=76)\end{array}$ \\
\hline $\begin{array}{l}\text { All patients: } \\
\text { Morbidity } \\
\text { Mortality }\end{array}$ & $\begin{array}{l}0.8 \\
0.5\end{array}$ & $\begin{array}{l}0.5 \\
0.5\end{array}$ & $\begin{array}{l}2 \cdot 7 \\
2 \cdot 7 \dagger\end{array}$ & $\begin{array}{l}7.9 * \\
7.9 \dagger\end{array}$ \\
\hline $\begin{array}{l}\text { of } 95-104 \mathrm{~mm} \mathrm{Hg} \text { : } \\
\text { Morbidity } \\
\text { Mortality }\end{array}$ & & $\begin{array}{l}1.6 \\
0.8\end{array}$ & $\begin{array}{l}2 \cdot 2 \\
2 \cdot 2\end{array}$ & $\begin{array}{l}10.9 * \\
10.9 *\end{array}$ \\
\hline $\begin{array}{l}\text { Patients with blood pressures } \\
\text { of over } 104 \mathrm{~mm} \mathrm{Hg} \text { : } \\
\text { Morbidity } \\
\text { Mortality }\end{array}$ & & 0.5 & $\begin{array}{l}3 \cdot 1 \dagger \\
3 \cdot 1 \dagger\end{array}$ & $\begin{array}{l}3 \cdot 3 \dagger \\
3 \cdot 3 \dagger\end{array}$ \\
\hline
\end{tabular}

${ }^{*} \mathrm{p}<0.001,+\mathrm{p}<0.05$ compared with morbidity and mortality in group 1 .

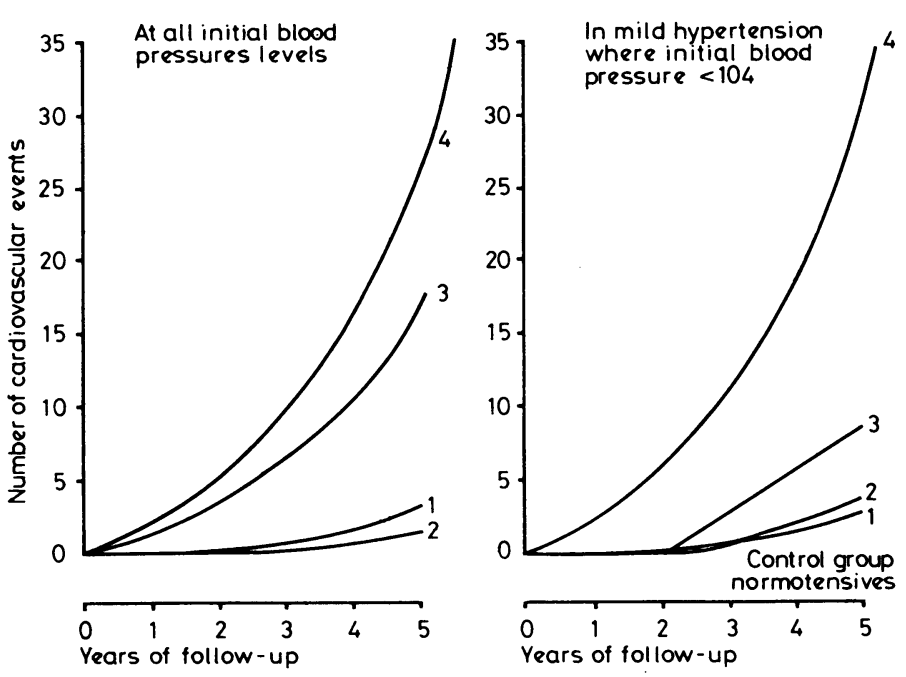

Cumulative cardiovascular events at all initial blood pressure levels and in mild hypertension where initial blood pressure was less than 104 .

\section{Discussion}

The National High Blood Pressure Programme (1970) in the United States posed two fundamental questions about the treatment of hypertension. It asked whether a systematic approach to antihypertensive treatment compared with community care was effective in reducing five-year mortality for all hypertensive adults in the community and whether the benefits of treatment exceeded toxicity in mild as well as moderate hypertension. Our study gives an affirmative answer to both these questions.

Most studies are either self-selecting like the Australian survey ${ }^{5}$ or have a population of such widespread origin that it is not easy to refer to any problems of "community care." We have the advantage that all our patients came from the same area and were identified by the same extensive and detailed popula- 
tion survey with a $92^{\circ},{ }_{0}^{\prime}$ contact response. ${ }^{6}$ Furthermore, all those thought to be hypertensive on the first home visit were followed up and our drop-out rate from the clinic was negligible (less than $1 \%$ ), whereas surveys that were not concentrated in one centre did not achieve the same scale of response. For example, treatment and follow-up was discontinued in $25-30 \%$ of patients of the Hypertension Detection and Follow-up Programme survey in America ${ }^{3}$ and $35 \%$ in the Australian survey. ${ }^{5}$ We believe that our one-centre approach therefore gives a more useful and accurate practical picture of the effects of medical intervention in the treatment of hypertension.

The diagnosis of hypertension was stricter in our case than others and our definition of mild hypertension was a diastolic pressure of $95-104 \mathrm{~mm} \mathrm{Hg}$ compared, for example, with the Australian $^{5}$ definition of up to $110 \mathrm{~mm} \mathrm{Hg}$ diastolic. Success of treatment was also judged severely in our series as group 2 (well-controlled) were defined as those whose blood pressure was restored to the desired level of less than $140 / 95 \mathrm{~mm} \mathrm{Hg}$ on $80^{\circ}$ of recordings. In many series our group 3 , defined by us as less well-controlled patients with $20 \%$ of their recordings in excess of $140 / 95 \mathrm{~mm} \mathrm{Hg}$, might well be regarded as wellcontrolled.

Earlier studies ${ }^{7}{ }^{8}$ have found a disappointing reduction in morbidity and mortality from ischaemic heart disease, though they have confirmed the protective effect of treatment on the incidence of cerebrovascular disease. The HDFP survey ${ }^{3}$ showed a reduction from 56 to 30 deaths in the more actively treated group, and the Australian workers ${ }^{5}$ reported 70 ischaemic trial end-points in their active group and 88 in the placebo group. Our results showed a more encouraging reduction from 16 incidents per 100 subjects to only 1.2 (compared with 1.3 in the normotensives). Those whose control was less good also showed a reduction, but those with diastolic pressures of over $105 \mathrm{~mm}$ $\mathrm{Hg}$ experienced little benefit compared with untreated subjects. These findings show that the better the control the more pronounced the reduction in morbidity for both ischaemic heart disease and cerebrovascular disease.

The question whether beta-blocking agents are more effective than other drugs in reducing the incidence of vascular complications-particularly ischaemic heart disease-is controversial. In our study $98 \%$ of patients were treated with beta-blocking agents. Our uncontrolled group showed a significantly increased mortality and morbidity for both types of vascular disease, which was reduced to normal in the well-controlled group. Group 3 showed intermediate results, with patients with higher initial pressures showing less benefit. The difference in our results from those of other groups could be attributed, in part, to the type of treatment-namely, beta-blocking agents. We used these agents almost exclusively and we cannot compare the effects of other agents within our own series, although the efficacy of control of blood pressure with other agents has been shown to be comparable. It is reasonable to conclude that our choice of agent may have affected the results favourably. Nevertheless, control of blood pressure still appears to be the decisive factor, however this may be achieved. Other possible contributing factors to vascular disease can be discounted in this series as no advice was given about smoking or exercise and no specific advice was given on diet. It is interesting that the fall in mortality was significant even in those patients who did not achieve excellent control. The risks of morbidity in this group were higher than normal, but better than in those who received no treatment at all.

In a study by Berglund et $a l^{9} 635$ hypertensive men (diastolic $>115 \mathrm{~mm} \mathrm{Hg}$ on two occasions) were treated and the results compared with controls. The controls, however, were patients initially thought to be hypertensive as one casual reading showed a diastolic pressure of $115 \mathrm{~mm} \mathrm{Hg}$. Furthermore, 94 of the controls were later found to be hypertensive and were placed on treatment. They also had a high rate of non-participation. The end result at 4.3 years showed a difference of $6.9 \%$ against $3.6^{\circ}$, in the cumulative incidence of non-fatal and fatal myocardial infarctions, and Berglund et al concluded that: "Treat- ment of hypertension seems to prevent or postpone coronary heart disease." Although our controls were normotensive and our definition of hypertension was much stricter (diastolic $>95$ rather than $115 \mathrm{~mm} \mathrm{Hg}$ ) we agree with their conclusion.

Our study also differed from others ${ }^{3-5}$ in that we included an age- and sex-matched control group derived from the same community survey as our hypertensive subjects; this enabled us to determine the underlying rates of mortality and morbidity in the community. Our total mortality over five years in the normal group and in groups 2 and 3 compared favourably with the $6 \%$ mortality over five years in the stepped care group in the $\mathrm{HDFP}^{3}$ in the United States but accorded more closely with the fatal trial end-points in the treated groups in the Australian survey. ${ }^{5}$

When the patients in groups 2 and 3 were divided on the basis of whether they were treated in the hospital clinic or in the community, thus making them more comparable to the groups in the American survey, ${ }^{3}{ }^{4}$ then the results of the hospital clinic compared with community care coincided almost exactly with the results of group 2 and group 3 . This could be used to justify special hypertensive clinics in hospital and suggests that having special clinics significantly improves the results of treatment. It does not, of course, decide whether the effect of special clinics would be the same if these were operated in the community rather than a hospital. Some sections of the population now receive special treatment from their practitioners or in health centres.

We conclude that our study presents two central findings. Firstly, that morbidity and mortality from vascular disease are reduced by good control of blood pressure in mild as well as moderate hypertension and in both sexes at all ages studied. Control of hypertension does "prevent or postpone cardiovascular disease." "Secondly, we conclude that even less than excellent control has significant benefits, particularly in relation to vascular morbidity. We also found that care in a hospital clinic provided better control than community care and that it is both possible and practical to detect and treat hypertension at relatively low cost. As many cardiovascular events occur in hypertension when the patient is in the most productive period of his life with major responsibilities and at the height of his career, any cost-benefit analysis of treatment should show definite benefits. We therefore believe that more attention should be directed to the detection of the early asymptomatic phase of hypertension and its treatment.

\section{References}

1 Veterans Administration Cooperative Study Group on Antihypertensive Agents. Effects of treatment on morbidity in hypertension: results in patients with diastolic blood pressure averaging 115 through $129 \mathrm{~mm} \mathrm{Hg}$. f $A M A$ 1967;202:1028-34.

2 Veterans Administration Cooperative Study Group on Antihypertensive Agents. Effects of treatment on morbidity in hypertension: results in patients with diastolic blood pressure averaging 90 through $114 \mathrm{~mm} \mathrm{Hg}$. f $A M A$ 1970;213:1143-52.

${ }^{3}$ Hypertension Detection and Follow-Up Program Cooperative Group. Five-year findings of the hypertension detection and follow-up program. Reduction in mortality of persons with high blood pressure, including mild hypertension. $7 A M A 1979 ; 242 \cdot 2562-71$.

${ }^{4}$ Hypertension Detection and Follow-Up Program Cooperative Group. Five-year findings of the hypertension detection and follow-up program. II. Mortality by race-sex and age. $\mathcal{f} A M A$ 1979;242:2572-7.

5 The Management Committee. The Australian therapeutic trial in mild hypertension. Lancet $1980 ; \mathrm{i}: 1261-7$.

6 Trafford JAP, Ireland R, McGonigle R, Sharpstone P, Halford-Maw L, Evans R. Screening for hypertension: a hospital-based home-visiting programme. Br Med f 1979;ii:1556.

7 Smith WM. US Public Health Service Hospitals Cooperative Study Group. Treatment of mild hypertension. Results of a ten-year intervention trial. Circ Res 1977;40, suppl $1: 98-105$.

${ }^{8}$ Hamilton M, Thompson EN, Wisniewski TKM. The role of blood pressure control in preventing complications of hypertension. Lancet $1964 ; \mathrm{i}: 235-8$.

${ }^{9}$ Berglund G, Wilkelmsen L, Sannerstedt R, et al. Coronary heart-disease after treatment of hypertension. Lancet $1978 ; \mathrm{i}: 1-5$. 